\title{
CAMP Stimulates Bicarbonate Secretion across Normal, but Not Cystic Fibrosis Airway Epithelia
}

\author{
Jeffrey J. Smith and Michael J. Welsh \\ With the technical assistance of Dapka N. Baccam \\ Departments of Pediatrics, Internal Medicine, and Physiology and Biophysics, Howard Hughes Medical Institute, \\ University of Iowa College of Medicine, Iowa City, Iowa 52242
}

\begin{abstract}
Adenosine 3',5'-cyclic monophosphate stimulates chloride $\left(\mathrm{Cl}^{-}\right)$ secretion across airway epithelia. To determine whether CAMP also stimulates $\mathrm{HCO}_{3}^{-}$secretion, we studied cultured canine and human airway epithelial cells bathed in a $\mathrm{HCO}_{3}^{-} / \mathrm{CO}_{2}$-buffered, $\mathrm{Cl}^{-}$-free solution. Addition of forskolin stimulated an increase in short-circuit current that was likely a result of bicarbonate secretion because it was inhibited by a $\mathrm{HCO}_{3}^{-}$-free solution, by addition of the carbonic anhydrase inhibitor, acetazolamide, or by mucosal addition of the anion channel blocker, diphenylamine 2-carboxylate. The current was dependent on $\mathrm{Na}^{+}$because it was inhibited by removal of $\mathrm{Na}^{+}$from the submucosal bathing solution, by addition of the $\mathrm{Na}^{+}$pump inhibitor, ouabain, or by addition of amiloride $(1 \mathrm{mM})$ to the submucosal solution. An increase in cytosolic $\mathrm{Ca}^{2+}$ produced by addition of a $\mathrm{Ca}^{2+}$ ionophore also stimulated short-circuit current. These data suggest that $\mathrm{CAMP}$ and $\mathrm{Ca}^{2+}$ stimulate $\mathrm{HCO}_{3}^{-}$secretion across airway epithelium, and suggest that $\mathrm{HCO}_{3}^{-}$leaves the cell across the apical membrane via conductive pathways. These results may explain previous observations that the short-circuit current across airway epithelia was not entirely accounted for by the sum of $\mathrm{Na}^{+}$absorption and $\mathrm{Cl}^{-}$ secretion. The cAMP-induced secretory response was absent in cystic fibrosis (CF) airway epithelial cells, although $\mathrm{Ca}^{2+}$-stimulated secretion was intact. This result suggests that $\mathrm{HCO}_{3}^{-}$ exit at the apical membrane is through the $\mathrm{Cl}^{-}$channel that is defectively regulated in $\mathrm{CF}$ epithelia. These results suggest the possibility that a defect in $\mathrm{HCO}_{3}^{-}$secretion may contribute to the pathophysiology of CF pulmonary disease. (J. Clin. Invest. 1992.89:1148-1153.) Key words: $\mathrm{pH} \cdot \mathrm{HCO}_{3}^{-}$transport $\bullet$ bicarbonate conductance
\end{abstract}

\section{Introduction}

Olver et al. (1) first reported that airway epithelia absorb sodium $\left(\mathrm{Na}^{+}\right)$and secrete chloride $\left(\mathrm{Cl}^{-}\right)$. They observed that native canine tracheal epithelia bathed in Ringer's solution developed a lumen negative, transepithelial potential difference, suggesting that airway epithelia either absorb cations, secrete

Portions of this work were published in 1990 (J. Cell. Biol. 111:440A). Address correspondence and reprint requests to Dr. J. J. Smith, Department of Pediatrics, University of Iowa College of Medicine, Iowa City, Iowa 52242.

Received for publication 28 August 1991 and in revised form 15 November 1991.

J. Clin. Invest.

(C) The American Society for Clinical Investigation, Inc.

0021-9738/92/04/1148/06 \$2.00

Volume 89, April 1992, 1148-1153 anions, or both. Under short-circuit conditions they measured a net flux of ${ }^{36} \mathrm{Cl}$ toward the airway lumen, and ${ }^{22} \mathrm{Na}$ toward the submucosa of tracheal epithelia. Their observation that airway epithelia absorb $\mathrm{Na}^{+}$and secrete $\mathrm{Cl}^{-}$has been confirmed by numerous investigators studying nasal, tracheal, and bronchial epithelia from several species (for review see reference 2).

Since that initial report of transport across airway epithelium, the unidirectional flux of ${ }^{22} \mathrm{Na}$ and ${ }^{36} \mathrm{Cl}$ across native canine tracheal epithelia has been measured under short-circuit conditions by several investigators. Widdicombe et al. (3), and later $\mathrm{Al}-\mathrm{Bazzaz}$ and $\mathrm{Al}-\mathrm{Awqati}(4)$, found that $\mathrm{Na}^{+}$absorption and $\mathrm{Cl}^{-}$secretion accounted for most of the short-circuit current $\left(\mathrm{I}_{\mathrm{sc}}\right)^{1}$ although a small residual ion flux was present. Addition of dibutyryl cAMP stimulated an increase in both net $\mathrm{Cl}^{-}$secretion and this residual current (5). When airway epithelia were bathed in $\mathrm{Cl}^{-}$-free solution, the net flux of $\mathrm{Na}^{+}$accounted for only $65 \%$ of the $I_{s c}(4)$. In addition, when airway epithelia were exposed to furosemide, an inhibitor of basolateral $\mathrm{Cl}^{-}$entry, $\mathrm{Na}^{+}$absorption and $\mathrm{Cl}^{-}$secretion together accounted for only $55 \%$ of the $\mathrm{I}_{\mathrm{sc}}(6)$.

These studies suggest that additional ion species may be transported across the airway. This notion was supported by our observation that cAMP-mediated agonists stimulated an increase in $\mathrm{I}_{\mathrm{sc}}$ when airway monolayers were bathed in $\mathrm{HCO}_{3}^{-}$/ $\mathrm{CO}_{2}$-buffered, $\mathrm{Cl}^{-}$-free solution, but not when both $\mathrm{Cl}^{-}$and $\mathrm{HCO}_{3}^{-}$were excluded from the bathing solution. Furthermore, this increase in $\mathrm{I}_{\mathrm{sc}}$ was inhibited by diphenylamine 2-carboxylate (DPC), an anion channel blocker, but not by $10 \mu \mathrm{M}$ amiloride, $\mathrm{a} \mathrm{Na}^{+}$channel blocker. These findings led us to investigate whether airway epithelia secrete $\mathrm{HCO}_{3}^{-}$, which might account for the unexplained residual ion flux noted in previous reports.

\section{Methods}

Cell culture. Airway cells were isolated from canine tracheal and human nasal epithelia using enzyme digestion, as previously described (7, 8). Nasal polyp specimens were obtained, after polypectomy, for upper airway obstruction in patients with allergic rhinitis (control) or cystic fibrosis (CF). Freshly isolated cells were seeded on collagen-coated, semipermeable membranes (Millicell-HA; Millipore, Bedford, MA), and incubated at $37^{\circ} \mathrm{C}$ in an humidified atmosphere of $5 \% \mathrm{CO}_{2}$ in air. Culture media, a mixture of 50\% Dulbecco's modified Eagle medium and 50\% Ham's F12 medium (DME/F12), was supplemented with 10 $\mu \mathrm{g} / \mathrm{ml}$ insulin, $5 \%$ fetal calf serum (Sigma Chemical Co., St. Louis, MO), $10 \mathrm{mM}$ nonessential amino acids (Irvine Scientific, Santa Ana, CA), $100 \mathrm{U} / \mathrm{ml}$ penicillin, and $100 \mu \mathrm{g} / \mathrm{ml}$ streptomycin.

1. Abbreviations used in this paper: CF, cystic fibrosis; CPT- CAMP,8(4-chlorophenylthio)-cAMP; DPC, diphenylamine 2-carboxylate; $\mathbf{G}_{t}$, transepithelial conductance; IBMX, 3-Isobutyl 1-methylxanthine; $\mathrm{I}_{\mathrm{sc}}$, short-circuit current; NMDG, $N$-methyl D-glucamine. 
Table I. Composition of Bathing Solutions

\begin{tabular}{rrrrrrrrrr}
\hline No. & $\mathrm{Na}^{+}$ & $\mathrm{NMDG}^{+}$ & $\mathrm{Cl}^{-}$ & Gluconate & Aspartate & $\mathrm{HCO}_{3}^{-}$ & Hepes & $\mathrm{SO}_{4}^{-2}$ & $\mathrm{CO}_{2}$ \\
\hline 1 & 143 & 0 & 0 & 119 & 0 & 24 & 0 & 6.4 & $5 \%$ \\
2 & 0 & 119 & 0 & 119 & 0 & $24^{*}$ & 0 & 6.4 & $5 \%$ \\
3 & 119 & 0 & 0 & 119 & 0 & 0 & 10 & 6.4 & $0 \%$ \\
4 & 0 & 119 & 0 & 0 & 119 & 24 & 0 & 6.4 & $5 \%$ \\
5 & 143 & 0 & 0 & 0 & 119 & 24 & 0 & 6.4 & $5 \%$ \\
6 & 143 & 0 & 0 & 119 & 0 & 24 & 0 & $0^{\ddagger}$ & $5 \%$ \\
7 & 119 & 0 & 119 & 0 & 0 & 0 & 10 & 6.4 & $0 \%$ \\
8 & 143 & 0 & 119 & 0 & 0 & 24 & 0 & 6.4 & $5 \%$ \\
& & & & & & & & &
\end{tabular}

Solutions contained (mM): $\mathrm{CaSO}_{4}$ 2.4-3.2, $\mathrm{MgSO}_{4} 1.2, \mathrm{~K}_{2} \mathrm{HPO}_{4} 2.4$, and $\mathrm{KH}_{2} \mathrm{PO}_{4} 1.6(\mathrm{pH}=7.4) ;{ }^{*}$ Choline bicarbonate substituted for $\mathrm{NaHCO}_{3} ;{ }^{\ddagger}$ Calcium acetate and $\mathrm{MgCO}_{3}$ substituted for $\mathrm{CaSO}_{4}$ and $\mathrm{MgSO}_{4}$.

Short-circuit current measurements. Epithelial monolayers were mounted in modified Ussing chambers 4-7 d after seeding. They were bathed in symmetrical saline solutions (see Table I), warmed to $37^{\circ} \mathrm{C}$, and gassed with a $95 \% \mathrm{O}_{2}-5 \% \mathrm{CO}_{2}$ mixture $\left(\mathrm{HCO}_{3}^{-}\right.$-free solutions were gassed with $100 \% \mathrm{O}_{2}$ ). The primary bathing solution was $\mathrm{Cl}^{-}$-free Ringer's, consisting of (mM) Na gluconate $119, \mathrm{NaHCO}_{3} 24, \mathrm{~K}_{2} \mathrm{HPO}_{4}$ 2.4, $\mathrm{KH}_{2} \mathrm{PO}_{4} 1.6, \mathrm{CaSO}_{4} 3.2$, and $\mathrm{MgSO}_{4} 1.2, \mathrm{pH}=7.4$ (solution 1). For some experiments, this primary solution was modified using the ion substitutions listed in Table $\mathrm{I}$.

Short-circuit current $\left(\mathrm{I}_{\mathrm{sc}}\right)$ was recorded continuously; transepithelial conductance $\left(G_{t}\right)$ was measured every $50 \mathrm{~s}$ by clamping to $5-20$ $\mathrm{mV}$. Experiments were performed with either $\mathrm{KCl}$ or $\mathrm{Na}$ gluconate agar bridges connecting Ussing chambers to Calomel electrodes; $\mathrm{I}_{\mathrm{sc}}$ and $G_{t}$ responses were not affected by the type of bridge used. For all recordings, amiloride (final concentration $10 \mu \mathrm{M}$ ) was present in the mucosal solution to inhibit $\mathrm{Na}^{+}$absorption. 3-Isobutyl 1-methylxanthine (IBMX) was added simultaneously with forskolin.

For some experiments, native canine tracheal epithelia were mounted in Ussing chambers and bathed in $\mathrm{Cl}^{-}$-free solution (solution 1); $I_{s c}$ and $G_{t}$ were recorded, as noted above.

Reagents. Amiloride was a gift from Merck, Sharp and Dohme Research (West Point, PA). Isoproterenol was obtained from ElkinsSinn, Inc. (Cherry Hill, NJ), and diphenylamine 2-carboxylate (DPC) from Fluka Chem. Corp. (Ronkonkoma, NY). All other chemicals were purchased from Sigma Chemical Co. All drugs were prepared as stock solutions (1,000-fold higher concentration); vehicle alone was added to control monolayers for comparison. Control and experimental studies were performed in paired monolayers from the same seeding.

Statistical methods. Values are presented as means \pm SEM. Statistically significant differences between means were measured using paired and unpaired $t$ tests where appropriate; $P$ values $\leq 0.05$ were considered statistically significant.

\section{Results}

Bicarbonate secretion by airway epithelium. In $\mathrm{Cl}^{-}$-free solution (solution 1), canine airway monolayers had baseline electrical resistance and $\mathrm{I}_{\mathrm{sc}}$ of $1000 \pm 190 \Omega \cdot \mathrm{cm}^{2}$, and $2.1 \pm 0.5 \mu \mathrm{A} /$ $\mathrm{cm}^{2}$, respectively $(n=16)$. Human airway epithelial monolayers had slightly lower values, but the values for normal and CF monolayers were similar: $440 \pm 50$ and $460 \pm 80 \Omega \cdot \mathrm{cm}^{2}$, and $1.5 \pm 0.3$ and $1.5 \pm 0.2 \mu \mathrm{A} / \mathrm{cm}^{2}(n=10)$, respectively. Addition of $10 \mu \mathrm{M}$ amiloride to the mucosal solution decreased $\mathrm{I}_{\mathrm{sc}}$ to $1.0 \pm 0.3 \mu \mathrm{A} / \mathrm{cm}^{2}$ for canine cells, and to $0.4 \pm 0.2$ and $0.2 \pm 0.1$ $\mu \mathrm{A} / \mathrm{cm}^{2}$ for normal and CF nasal cells, respectively.
When forskolin, an activator of adenylate cyclase, was added to either the mucosal or submucosal solution, $I_{s c}$ and $G_{t}$ increased (Fig. 1). Several findings indicate that this response is mediated by an increase in intracellular cAMP concentration. First, addition of a membrane-permeable cAMP analogue, 8-(4-chlorophenylthio)adenosine $3^{\prime}, 5^{\prime}$-monophosphate (CPTcAMP), caused a similar increase in current (Fig. 2). Second, the increase in $\mathrm{I}_{\mathrm{sc}}$ was greater in magnitude when forskolin or CPT-cAMP were added in the presence of IBMX, an inhibitor of cAMP catabolism (shown for CPT-cAMP). Third, isoproterenol and prostaglandin $E_{2}$, both secretagogues which increase intracellular cAMP concentration, also stimulated $I_{s c}$ (shown for isoproterenol). Fourth, responses to each of these agonists were not additive, suggesting a common mechanism of action (shown for CPT-cAMP, forskolin and isoproterenol). These findings support the notion that the actions of these secretagogues are mediated by an increase in intracellular cAMP concentration.

To investigate the ionic basis of the cAMP-stimulated $\mathrm{I}_{\mathrm{sc}}$, we examined the effect of several agents that inhibit ion transport processes in airway epithelia. Mucosal addition of an anion channel blocker, DPC, inhibited the cAMP-mediated increase in $I_{s c}$ (Fig. 1). $G_{t}$ also decreased by $10 \%$ after DPC addition. These findings suggested that cAMP may stimulate $\mathrm{HCO}_{3}^{-}$secretion via apical anion channels, although DPC might have effects other than anion channel blockade. As an alternative, we considered the possibility that CAMP may stimulate amiloride-insensitive $\mathrm{Na}^{+}$absorption.

We examined the effect of forskolin in monolayers that were bathed in either $\mathrm{Na}^{+}$-free or $\mathrm{HCO}_{3}^{-}$-free solutions (solutions 2 and 3, respectively). In each case, the response to forskolin was attenuated (Fig. 3), indicating that both $\mathrm{Na}^{+}$and $\mathrm{HCO}_{3}^{-}$were required for the increase in current.

Because $\mathrm{HCO}_{3}^{-}$-dependence might involve the conversion of $\mathrm{CO}_{2}$ and $\mathrm{H}_{2} \mathrm{O}$ to $\mathrm{H}^{+}$and $\mathrm{HCO}_{3}^{-}$, we examined the effect of acetazolamide, an inhibitor of carbonic anhydrase, on the forskolin-stimulated response. Addition of acetazolamide caused an immediate decrease in $I_{s c}$ (Fig. 4). In contrast, inhibitors of $\mathrm{HCO}_{3}^{-}$-coupled transport, 4,4'-diisothiocyanatostilbene-2,2'disulfonate (200 $\mu \mathrm{M}$ DIDS), and 4-acetamido-4'-isothiocyanatostilbene $2,2^{\prime}$-disulfonate ( $250 \mu \mathrm{M}$ SITS), did not attenuate the response to forskolin ( $n=4$ each).

These results suggested that the forskolin-stimulated current was due to $\mathrm{HCO}_{3}^{-}$secretion, and that $\mathrm{Na}^{+}$might be

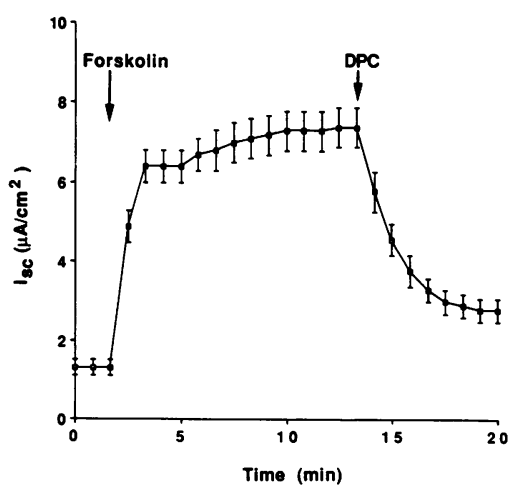

Figure 1. Effect of 10 $\mu \mathrm{M}$ forskolin on $\mathrm{I}_{\mathrm{sc}}$ in canine epithelial monolayers bathed in $\mathrm{Cl}^{-}$-free solution (solution 1, see Table I). IBMX (100 $\mu \mathrm{M})$ was added simultaneously with mucosal addition of forskolin (see Methods). Mucosal addition of $1 \mathrm{mM}$ DPC inhibited the increase in $I_{\mathrm{sc}}$. Forskolin increased $\mathrm{G}_{\mathrm{t}}$ from $0.81 \pm 0.03$ to $0.97 \pm 0.04 \mathrm{mS} / \mathrm{cm}^{2}: \mathrm{G}_{\mathrm{t}}$ decreased to $0.89 \pm 0.04 \mathrm{mS} / \mathrm{cm}^{2}$ after addition of DPC $(P<0.05)$. Values are means \pm SEM; $n=10$. 


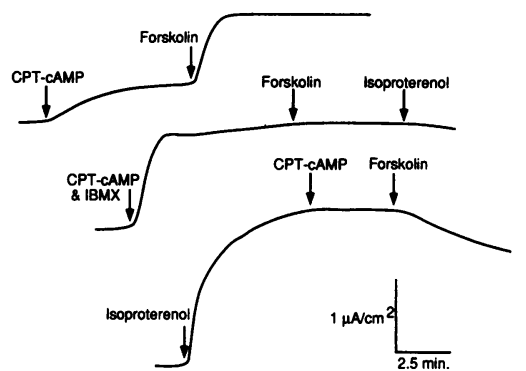
arrows; $100 \mu \mathrm{M}$ IBMX was added simultaneously with CPT-cAMP where indicated. Values are representative tracings from 3 monolayers.

required for the process. To test this possibility, monolayers were bathed in symmetrical $N$-methyl D-glucamine aspartate solution (NMDG aspartate, solution 4). After 15-20 min in the $\mathrm{Na}^{+}$-free solution, $\mathrm{Na}$ aspartate (solution 5) replaced either the mucosal or the submucosal NMDG aspartate. Establishing this transepithelial $\mathrm{Na}^{+}$concentration gradient resulted in a current in the direction expected for passive $\mathrm{Na}^{+}$permeability (Fig. 5). Subsequent addition of forskolin stimulated an increase in DPC-sensitive current in those monolayers exposed to $\mathrm{Na}^{+}$at the submucosal surface, but not those exposed to $\mathrm{Na}^{+}$at the mucosal surface. These results indicate that forskolin did not stimulate $\mathrm{Na}^{+}$absorption. Taken together with the $\mathrm{HCO}_{3}^{-}$dependence (Fig. 3), these results suggest that forskolin stimulates $\mathrm{Na}^{+}$-dependent, $\mathrm{HCO}_{3}^{-}$secretion.

To further investigate the role of $\mathrm{Na}^{+}$in supporting $\mathrm{HCO}_{3}^{-}$ secretion, we examined the effect of $\mathrm{Na}^{+}$transport inhibitors on forskolin-stimulated $I_{s c}$. When monolayers were preincubated for 20-30 min with ouabain, an inhibitor of Na-K-ATPase activity, the response to forskolin was attenuated (Fig. 6). Ouabain attenuated this response only when added to the submucosal solution. This suggests that the transmembrane $\mathrm{Na}^{+}$ gradient maintained by Na-K-ATPase is required for $\mathrm{HCO}_{3}^{-}$ secretion.

$\mathrm{Na}^{+}$might be required for $\mathrm{HCO}_{3}^{-}$secretion in order to mediate the efflux of $\mathrm{H}^{+}$across the basolateral membrane $\left(\mathrm{Na}^{+} / \mathrm{H}^{+}\right.$ exchange) when $\mathrm{HCO}_{3}^{-}$exits across the apical membrane. To test this possibility, we examined the effect of $1 \mathrm{mM}$ amiloride (For all experiments the mucosal solution contained $10 \mu \mathrm{M}$ amiloride [see Methods]) on the forskolin-stimulated response; this high concentration of amiloride inhibits $\mathrm{Na}^{+} / \mathrm{H}^{+}$exchange. Addition of $1 \mathrm{mM}$ amiloride to the submucosal solution caused an immediate decrease in current (Fig. 7). In con-

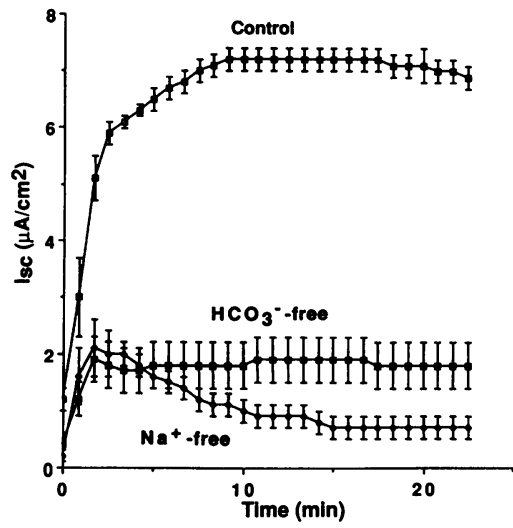

Figure 3. Effect of $\mathrm{Na}^{+}$ free and $\mathrm{HCO}_{3}^{-}$-free solution on $\mathrm{I}_{\mathrm{sc}}$ response to forskolin (canine monolayers). Control (solution 1), $\mathrm{Na}^{+}$-free (solution 2), and $\mathrm{HCO}_{3}^{-}$-free (solution 3) solutions are $\mathrm{Cl}^{-}$-free (see Table I). Forskolin was added at time zero. Values are means $\pm \mathrm{SEM} ; n=4$.

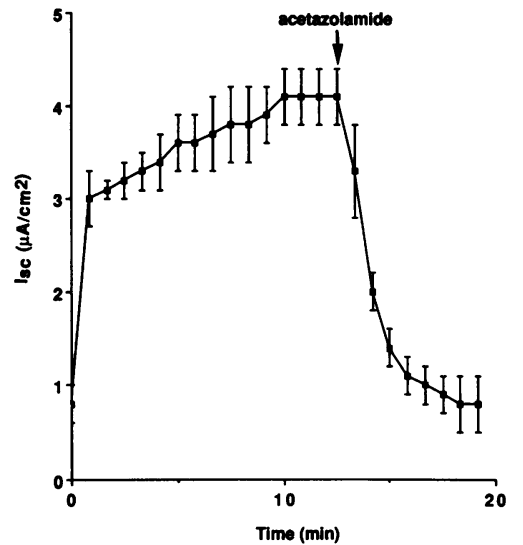

trast, addition of $1 \mathrm{mM}$ amiloride to the mucosal solution had no effect $(n=4)$. Moreover, addition of a lower concentration $(10 \mu \mathrm{M})$ of amiloride to the submucosal solution had no effect. The inhibitory effects of amiloride and ouabain suggest that forskolin induces a recycling of $\mathrm{Na}^{+}$across the basolateral membrane via the $\mathrm{Na}^{+} / \mathrm{H}^{+}$exchanger and $\mathrm{Na}-\mathrm{K}-\mathrm{ATPase}$.

These results suggest that cAMP stimulates $\mathrm{HCO}_{3}^{-}$secretion by the following mechanism: Carbonic anhydrase converts $\mathrm{CO}_{2}$ and $\mathrm{H}_{2} \mathrm{O}$ to $\mathrm{H}^{+}$and $\mathrm{HCO}_{3}^{-} . \mathrm{H}^{+}$exits at the basolateral membrane and $\mathrm{HCO}_{3}^{-}$exits across the apical membrane (For details, see Discussion). If $\mathrm{HCO}_{3}^{-}$exits across the apical membrane through ion channels, the rate of transport should be influenced by the membrane potential. To determine whether membrane depolarization decreases the rate of $\mathrm{HCO}_{3}^{-}$ transport, we examined the effect of barium $\left(\mathrm{Ba}^{2+}\right)$, a potassium $\left(\mathrm{K}^{+}\right)$channel blocker known to depolarize airway epithelia (9). Fig. 8 shows that $\mathrm{Ba}^{2+}$ caused an immediate inhibition of $\mathrm{I}_{\mathrm{sc}}$, supporting the notion that $\mathrm{HCO}_{3}^{-}$crosses the apical membrane via a conductive pathway.

cAMP-stimulated $\mathrm{HCO}_{3}^{-}$secretion was also observed in native airway epithelium mounted in Ussing chambers and bathed in $\mathrm{HCO}_{3}^{-} / \mathrm{CO}_{2}$-buffered, $\mathrm{Cl}^{-}$-free solution (solution 1). Forskolin stimulated an increase in $\mathrm{I}_{s c}\left(71 \pm 28 \mu \mathrm{A} / \mathrm{cm}^{2}, n=3\right)$; secretion was blocked by mucosal addition of DPC (Fig. 9).

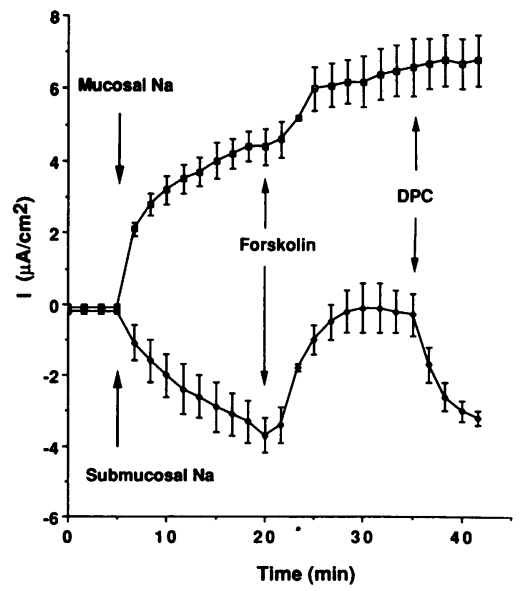

Figure 5. Effect of mucosal or submucosal $\mathrm{Na}^{+}$on forskolin-stimulated $\mathrm{I}_{\mathrm{sc}}$. Canine monolayers were bathed in symmetric NMDG aspartate solution (solution 4); $\mathrm{Na}$ aspartate (solution 5) replaced NMDG asparate in either the mucosal or submucosal solution (first arrow). Establishing this $\mathrm{Na}^{+}$concentration gradient resulted in a current in the direction expected for a passive $\mathrm{Na}^{+}$permeability. Forskolin and DPC were added at the times indicated by arrows $(n=3)$. 


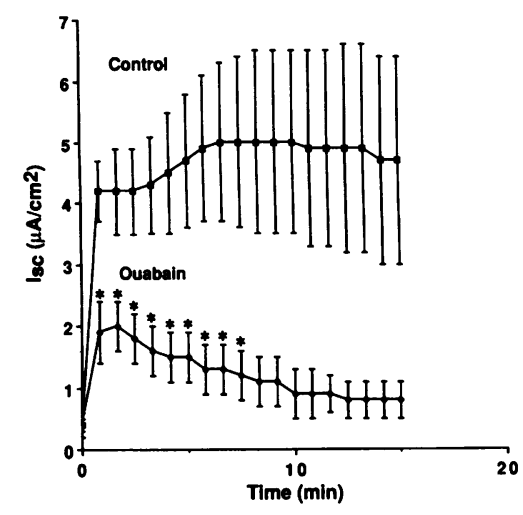

Figure 6. Effect of ouabain $(10 \mu \mathrm{M})$ on forskolin-stimulated $\mathrm{I}_{\mathrm{sc}}$. Canine monolayers were bathed in solution 1 . ${ }^{*}$ Increase in $\mathrm{I}_{\boldsymbol{x}}$ significantly different from control. $n=3$.
Bicarbonate and chloride secretion. Because cAMP also stimulates $\mathrm{Cl}^{-}$secretion by airway epithelia (2), we asked whether $\mathrm{HCO}_{3}^{-}$secretion accounts for part of the increase in $\mathrm{I}_{\mathbf{s c}}$ when epithelia are bathed in solution containing both $\mathrm{Cl}^{-}$and $\mathrm{HCO}_{3}^{-}$. If secretion of $\mathrm{Cl}^{-}$and $\mathrm{HCO}_{3}^{-}$are independent, we would expect the secretory responses to be additive. Fig. 10 shows that the response to forskolin was similar when monolayers were bathed in solutions containing either $\mathrm{Cl}^{-}, \mathrm{HCO}_{3}^{-}$, or both. These results suggest that cAMP-mediated $\mathrm{Cl}^{-}$and $\mathrm{HCO}_{3}^{-}$secretion are not independent. Furthermore, because the $\mathrm{I}_{\text {sc }}$ responses were not additive, $\mathrm{Cl}^{-}$and $\mathrm{HCO}_{3}^{-}$are unlikely to be secreted by different cell populations.

To further determine the relative contribution of $\mathrm{Cl}^{-}$secretion and $\mathrm{HCO}_{3}^{-}$secretion to the cAMP-induced increase in $\mathrm{I}_{\mathrm{sc}}$, we examined the effects of bumetanide and amiloride $(1 \mathrm{mM})$ that inhibit $\mathrm{Cl}^{-}(10)$ and $\mathrm{HCO}_{3}^{-}$(Fig. 7) secretion, respectively. Fig. 11 shows that bumetanide inhibited $81 \pm 2 \%$ of the forskolin-stimulated $\mathrm{I}_{\mathrm{sc}}$ when monolayers were bathed in $\mathrm{CO}_{2}$-free, $\mathrm{NaCl}$ solution (solution 7), and inhibited only $2 \pm 2 \%$ of the current when monolayers were bathed in $\mathrm{HCO}_{3}^{-} / \mathrm{CO}_{2}$-buffered, $\mathrm{Cl}^{-}$-free solution (solution 1). These results indicate that bumetanide inhibits $\mathrm{Cl}^{-}$secretion, but not $\mathrm{HCO}_{3}^{-}$secretion. When monolayers are bathed in solution containing both $\mathrm{Cl}^{-}$and $\mathrm{HCO}_{3}^{-}$, bumetanide inhibited only $33 \pm 7 \%$ of the $\mathrm{I}_{\mathrm{sc}}$; amiloride inhibited the remaining current (Fig. 11).

These results suggest that when epithelia are bathed in solution containing both anions, cAMP stimulates secretion of both $\mathrm{Cl}^{-}$and $\mathrm{HCO}_{3}^{-}$. However, the addition of bumetanide may have shifted current, due predominantly to $\mathrm{Cl}^{-}$secretion to $\mathrm{HCO}_{3}^{-}$secretion alone. The following results support this

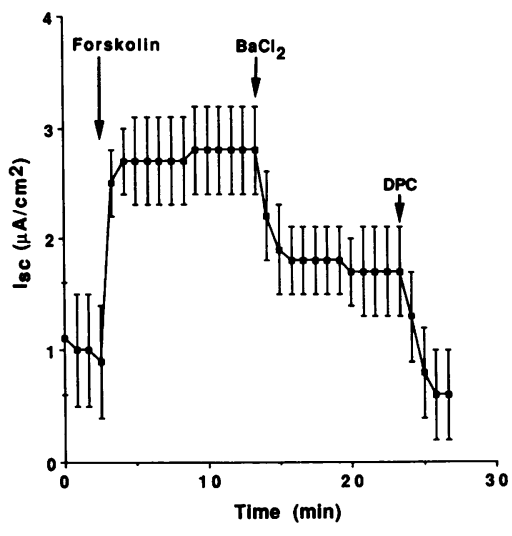

Figure 8. Effect of $\mathrm{Ba}^{2+}$ on forskolin-stimulated $I_{s c}$. Human airway monolayers were bathed in solution 6; forskolin $(10 \mu \mathrm{M}), \mathrm{BaCl}_{2}(1 \mathrm{mM})$ and DPC (1 mM) were added at the times indicated by arrows. $\mathrm{BaCl}_{2}$ was added to both submucosal and mucosal solutions. $n=3$.

possibility. In solutions containing both $\mathrm{Cl}^{-}$and $\mathrm{HCO}_{3}^{-}$(solution 8), the addition of acetazolamide did not inhibit forskolinstimulated $\mathrm{I}_{\mathrm{sc}}(n=7$, also reference 20$)$. However, when acetazolamide addition was preceded by bumetanide, which decreased $I_{s c}$ by $33 \pm 1 \%$, the subsequent addition of acetazolamide inhibited the remaining current $(n=8)$. These results suggest that $\mathrm{HCO}_{3}^{-}$secretion may be low in the presence of $\mathrm{Cl}^{-} ; \mathrm{HCO}_{3}^{-}$secretion may increase after $\mathrm{Cl}^{-}$secretion is blocked by bumetanide. These studies do not allow us to determine, in cultured or native epithelia, the absolute amount of $\mathrm{HCO}_{3}^{-}$secretion that occurs in the presence of $\mathrm{Cl}^{-}$.

Defective bicarbonate secretion by CF tracheal epithelia. Our results suggest that $\mathrm{HCO}_{3}^{-}$secretion occurs via a cAMPstimulated conductive pathway in the apical membrane. If that were the case, we expected that $\mathrm{HCO}_{3}^{-}$secretion would be defective in CF airway epithelia. To determine whether cAMP stimulates $\mathrm{HCO}_{3}^{-}$secretion across $\mathrm{CF}$ nasal airway epithelia, control (atopic) and CF nasal epithelial monolayers were bathed in $\mathrm{Cl}^{-}$-free solution (solution 1); addition of forskolin stimulated an increase in $\mathrm{I}_{\mathrm{sc}}$ in control, but not $\mathrm{CF}$ monolayers (Fig. 12). Although cAMP-mediated $\mathrm{Cl}^{-}$secretion is defective in $\mathrm{CF}$ airway epithelia, $\mathrm{Ca}^{2+}$-dependent $\mathrm{Cl}^{-}$secretion is intact (11). Thus, we examined whether agonists that increase $\left[\mathrm{Ca}^{2+}\right]_{c}$ stimulated $\mathrm{HCO}_{3}^{-}$secretion. Bradykinin, ATP, or a calcium ionophore (A23187) were used to stimulate $\mathrm{HCO}_{3}^{-}$secretion because these secretagogues increase $\left[\mathrm{Ca}^{2+}\right]_{\mathrm{c}}$ and stimulate $\mathrm{Cl}^{-}$ secretion across normal and CF airway epithelia $(12,13,14$, 15). In $\mathrm{Cl}^{-}$-free solution, each of these secretagogues alone stimulated a transient increase in $\mathrm{I}_{\mathrm{sc}}$ with both normal and $\mathrm{CF}$ epithelia (Figs. 12 and 13).

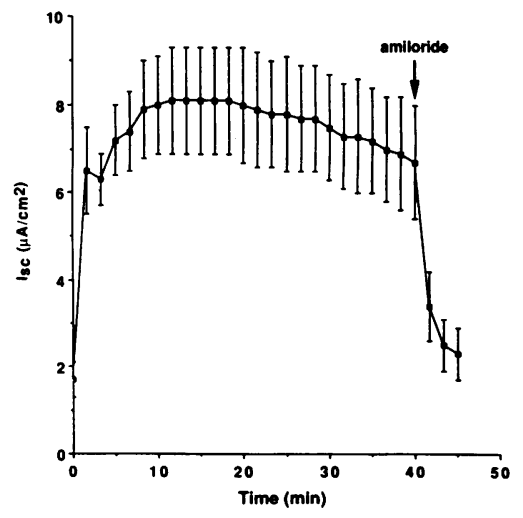

Figure 7. Effect of submucosal addition of amiloride on forskolin-stimulated $I_{s c}$. Forskolin was added at time zero, amiloride (1 $\mathrm{mM}$ ) was added at time indicated by the arrow. Canine monolayers were bathed in solution

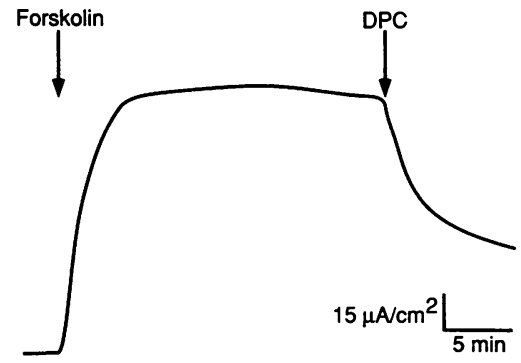

Figure 9. Effect of forskolin on $\mathrm{I}_{\mathrm{sc}}$ across native canine tracheal epithelia mounted in $\mathrm{HCO}_{3}^{-}$/ $\mathrm{CO}_{2}$-buffered, $\mathrm{Cl}^{-}$-free solution (solution 1). Representative tracing of $\mathrm{I}_{\mathrm{sc}}$ in response to forskolin and DPC $(0.5$ $\mathrm{mM}$ ) added to the mucosal solution at the

time indicated by arrows; amiloride $(10 \mu \mathrm{M})$ and indomethacin (1 $\mu \mathrm{M})$ were added to the mucosal solution $20 \mathrm{~min}$ before addition of forskolin. $G_{t}$ decreased from 2.1 to $1.6 \mathrm{mS} / \mathrm{cm}^{2}$ after addition of DPC. 


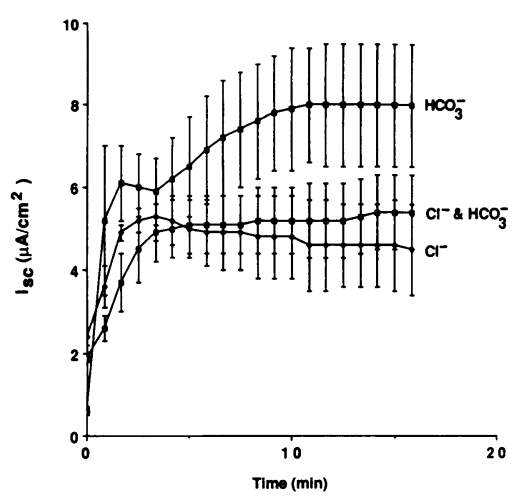

Figure 10. Effect of $\mathrm{Cl}^{-}$ and $\mathrm{HCO}_{3}^{-}$on forskolin-stimulated $\mathrm{I}_{\mathrm{sc}}$. Bathing solutions contained either $\mathrm{HCO}_{3}^{-}$(solution 1), $\mathrm{Cl}^{-}$(solution 7), or both (solution 8), as indicated. Forskolin was added at time zero. Mean $I_{s c}$ values between each group were not significantly different; $n$ $=3$ canine monolayers for each condition.

\section{Discussion}

Our results indicate that cAMP stimulates $\mathrm{HCO}_{3}^{-}$secretion across airway epithelial cells; the results and our interpretation are summarized by the model in Fig. 14. In cultured airway cells, carbonic anhydrase converts $\mathrm{H}_{2} \mathrm{O}$ and $\mathrm{CO}_{2}$ to $\mathrm{H}^{+}$and $\mathrm{HCO}_{3}^{-} \cdot \mathrm{H}^{+}$exits across the basolateral membrane via $\mathrm{Na}^{+} / \mathrm{H}^{+}$ exchange; $\mathrm{HCO}_{3}^{-}$exits across the apical membrane through anion channels. Basolateral Na-K-ATPase maintains a chemical driving force for $\mathrm{H}^{+}$efflux (the transmembrane $\mathrm{Na}^{+}$gradient); basolateral $\mathrm{K}^{+}$channels maintain an electrical driving force for $\mathrm{HCO}_{3}^{-}$efflux.

The evidence that cAMP stimulates $\mathrm{HCO}_{3}^{-}$transport through apical membrane anion channels is: (a) cAMP stimulates an increase in electrically conductive ion transport, i.e., $I_{\mathbf{s c}}$ and $G_{t}$ increase; $(b)$ both $I_{s c}$ and $G_{t}$ decrease after addition of the channel blocker, DPC; and $(c)$ addition of $\mathrm{Ba}^{2+}$, which inhibits basolateral $\mathrm{K}^{+}$channels and depolarizes airway epithelial cells, inhibited $I_{s c}$. Perhaps the most striking feature in this regard is the failure of cAMP to stimulate $\mathrm{HCO}_{3}^{-}$secretion in $\mathrm{CF}$ epithelial cells. Although cAMP-stimulated secretion was deficient, $\mathrm{Ca}^{2+}$-dependent stimulation was intact. These observations parallel previous observations on $\mathrm{Cl}^{-}$secretion: cAMPdependent $\mathrm{Cl}^{-}$secretion is deficient whereas $\mathrm{Ca}^{2+}$-stimulated $\mathrm{Cl}^{-}$secretion is normal in $\mathrm{CF}$ airway epithelia (16). Because the apical membrane of $\mathrm{CF}$ airway epithelia display defective regulation of apical $\mathrm{Cl}^{-}$channels, and because the protein mutated in $\mathrm{CF}$, cystic fibrosis transmembrane conductance regulator (CFTR), is itself a cAMP-regulated $\mathrm{Cl}^{-}$channel $(17,18,19)$, our data suggest that $\mathrm{HCO}_{3}^{-}$exit occurs through the same cAMP-regulated $\mathrm{Cl}^{-}$channel that is defective in $\mathrm{CF}$.

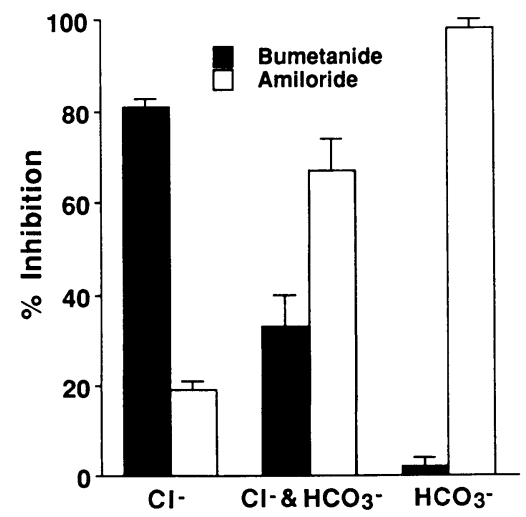

Figure 11. Effect of bumetanide and amiloride on forskolin-stimulated $\mathrm{I}_{\mathrm{sc}}$. Canine monolayers were bathed in solution containing either $\mathrm{HCO}_{3}^{-}$ (solution 1), $\mathrm{Cl}^{-}$(solution 7), or both (solution 8), as indicated; forskolin $(10 \mu \mathrm{M})$ was added to stimulate an increase in $\mathrm{I}_{\mathrm{sc}}$. Bumetanide $(100 \mu \mathrm{M})$ and amiloride $(1 \mathrm{mM})$ were added sequentially to

the submucosal solution. Percent inhibition of $I_{s c}$ bumetanide and amiloride is depicted; values are means $\pm \operatorname{SEM}(n=4)$.

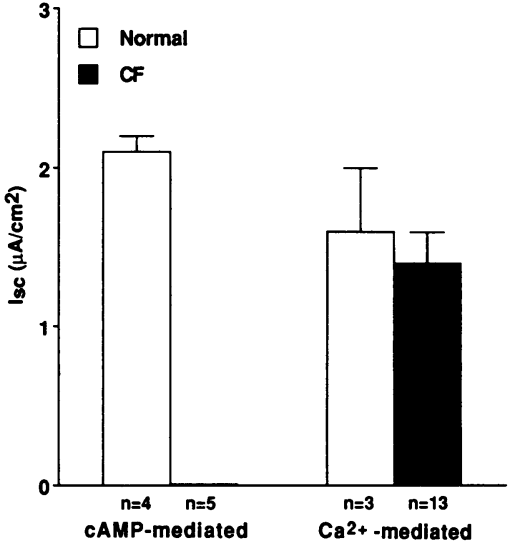

Our results indicate that $\mathrm{HCO}_{3}^{-}$secretion by airway epithelia is $\mathrm{Na}^{+}$-dependent (Fig. 3). The notion that $\mathrm{Na}^{+}$is recycled across the basolateral membrane via Na-K-ATPase and the $\mathrm{Na}^{+} / \mathrm{H}^{+}$exchanger is supported by the observations that $\mathrm{Na}^{+}$is required in the submucosal solution only (Fig. 5), and that secretion is inhibited by submucosal addition of ouabain or 1 $\mathrm{mM}$ amiloride (Figs. 6 and 7). Moreover, inhibition of $\mathrm{Na}^{+} / \mathrm{H}^{+}$ exchange by $1 \mathrm{mM}$ amiloride is consistent with acetazolamideinhibited $\mathrm{HCO}_{3}^{-}$secretion (Fig. 4), which should involve a mechanism of $\mathrm{H}^{+}$efflux to maintain intracellular $\mathrm{pH}$.

With the magnitude of $\mathrm{HCO}_{3}^{-}$secretion across airway epithelia possibly as great as $\mathrm{Cl}^{-}$secretion (Figs. 9 and 10), one might wonder why $\mathrm{HCO}_{3}^{-}$secretion was not apparent in previous studies. The results from two studies suggested at first glance that $\mathrm{HCO}_{3}^{-}$secretion was unlikely. First, Al-Bazzaz and Al-Awqati (4) reported that the removal of $\mathrm{HCO}_{3}^{-}$from the bath did not diminish cAMP-stimulated $\mathrm{I}_{\mathrm{sc}}$. Our results are identical (Fig. 10), but they are also consistent with a shift from $\mathrm{HCO}_{3}^{-}$and $\mathrm{Cl}^{-}$secretion to that of $\mathrm{Cl}^{-}$secretion alone (Figs. 10 and 11). Second, Widdicombe (20) observed that when monolayers were bathed in solutions containing $\mathrm{Cl}^{-}$and $\mathrm{HCO}_{3}^{-}$, the addition of acetazolamide did not attenuate the $I_{s c}$ response to cAMP. We also observed this lack of inhibition by acetazolamide alone. However, after inhibiting $\mathrm{Cl}^{-}$secretion with bumetanide, the subsequent addition of acetazolamide inhibited $I_{s c}$. These results are also consistent with the notion that the

\section{Normal}
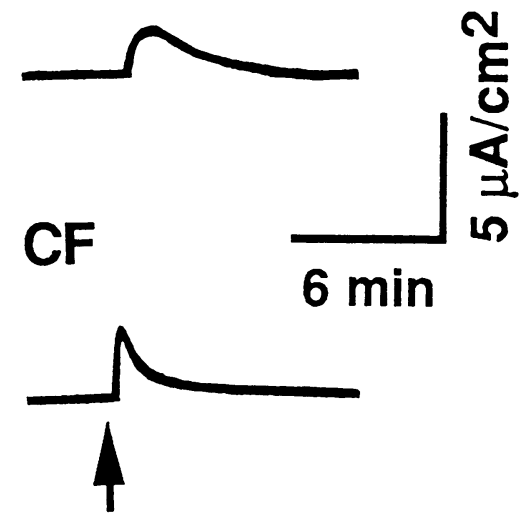

Figure 13. Effect of A23187 on $\mathrm{I}_{\mathrm{sc}}$ in normal and $\mathrm{CF}$ airway monolayers. Monolayers were bathed in $\mathrm{Cl}^{-}$-free solution (solution 1); A23187 $(1 \mu \mathrm{M})$ was added to the mucosal solution at the time indicated by the arrow; IBMX was not added. Values are tracings from representative monolayers. 


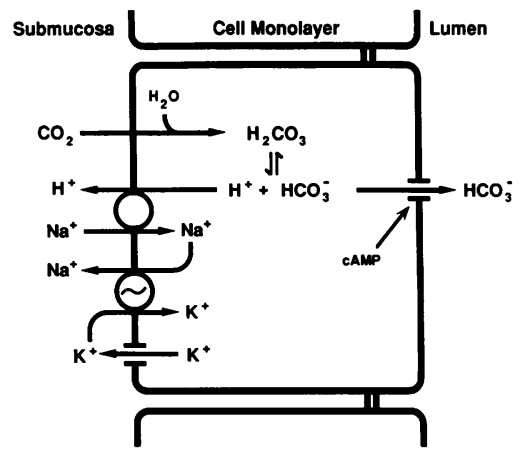

\section{References}

Figure 14. Model of cAMP-mediated, $\mathrm{HCO}_{3}^{-}$ secretion in cultured airway epithelium. Pathways involved in $\mathrm{HCO}_{3}^{-}$transport are shown; other transporters are omitted for clarity. For details see text. addition of acetazolamide may shift $\mathrm{Cl}^{-}$and $\mathrm{HCO}_{3}^{-}$secretion to $\mathrm{Cl}^{-}$secretion alone. Another reason that $\mathrm{HCO}_{3}^{-}$secretion might not have been previously identified is that $\mathrm{Cl}^{-}$-free solutions were also $\mathrm{CO}_{2}$-free (buffered with Hepes rather than $\left.\mathrm{HCO}_{3}^{-} / \mathrm{CO}_{2}\right)(21)$. Finally, although initial studies suggested that airway epithelia do not secrete $\mathrm{HCO}_{3}^{-}$, the simultaneous measurement of $I_{s c}$ and unidirectional ion flux across airway epithelia did indicate a cAMP-stimulated, residual ion flux that was heretofore unexplained (3-6). Our results suggest that $\mathrm{HCO}_{3}^{-}$secretion may have accounted for this puzzling observation.

What is the functional significance of $\mathrm{HCO}_{3}^{-}$secretion by airway epithelia? Is the rate of cAMP-stimulated $\mathrm{HCO}_{3}^{-}$secretion sufficient to alkalinize airway fluid? Although experimental data indicating alkalinization of the respiratory tract fluid has not been obtained, several factors support the possibility that such a process might be physiologically significant. First, the rate of $\mathrm{HCO}_{3}^{-}$secretion by native epithelium can be quite high (over $100 \mu \mathrm{A} / \mathrm{cm}^{2}$ in $\mathrm{Cl}^{-}$-free solution under short-circuit conditions). Although these conditions differ from those which occur in vivo, the capacity for $\mathrm{HCO}_{3}^{-}$secretion is substantial. Second, the volume of fluid into which $\mathrm{HCO}_{3}^{-}$would be secreted (the sol layer of airway secretions) is quite small, relative to the secretory surface area. The sol layer, which bathes airway cilia, is $\sim 5 \mu \mathrm{m}$ in depth, and is covered by a mucus or gel layer (22). This low ratio of airway fluid volume to secretory surface area, and the potentially high rate of $\mathrm{HCO}_{3}^{-}$secretion, would favor significant changes in $\mathrm{pH}$ following stimulation with secretagogues. Third, reports of $\mathrm{HCO}_{3}^{-}$concentrations of 50 $\mathrm{meq} / \mathrm{ml}(23)$ and $\mathrm{pH}$ values of 7.8-8.0 (24) in canine airway liquid are consistent with $\mathrm{HCO}_{3}^{-}$secretion into the airway lumen; $\mathrm{pH}$ values of human airway liquid (patients with tracheostomy) ranged from 6.1 to 7.9 (25). The alkalinization of airway fluid might be important to pulmonary defense mechanisms such as mucociliary clearance; for example, ciliary beat frequency is optimal at $\mathrm{pH}$ values of 7.0 to $9.0(26,27)$. These results suggest the possibility that a defect in $\mathrm{HCO}_{3}^{-}$secretion by airway epithelia may contribute to the pathophysiology of CF pulmonary disease.

\section{Acknowledgments}

We thank Phil Karp and Aurita Puga for culturing airway epithelial cells.

This work was supported by the March of Dimes Birth Defects Foundation (Basil O'Connor Starter Research Award 5-703), the National Cystic Fibrosis Foundation, and the National Heart, Lung, and Blood Institute (HL-42385). Dr. Smith was supported by the Parker B. Francis Foundation (Fellowship in Pulmonary Research).
1. Olver, R. E., B. Davis, M. G. Marin, and J. A. Nadel. 1975. Active transport of $\mathrm{Na}^{+}$and $\mathrm{Cl}^{-}$across the canine tracheal epithelium in vitro. Am. Rev. Respir. Dis. 112:811-815.

2. Welsh, M. J. 1987. Electrolyte transport by airway epithelia. Physiol. Rev. 67:1143-1184.

3. Widdicombe, J. H., I. F. Ueki, I. Bruderman, and J. A. Nadel. 1979. The effects of sodium substitution and ouabain on ion transport by dog tracheal epithelium. Am. Rev. Respir. Dis. 120:385-392.

4. Al-Bazzaz, F. J., and Q. Al-Awqati. 1979. Interaction between sodium and chloride transport in canine tracheal mucosa. J. Appl. Physiol. Respir. Environ. Exercise Physiol. 46:111-119.

5. Al-Bazzaz, F. J. 1981. Role of cyclic AMP in regulation of chloride secretion by canine tracheal mucosa. Am. Rev. Respir. Dis. 123:295-298.

6. Welsh, M. J. 1983. Inhibition of chloride secretion by furosemide in canine tracheal epithelium. J. Membr. Biol. 71:219-226.

7. Coleman, D. L., I. K. Tuet, and J. H. Widdicombe. 1984. Electrical properties of dog tracheal epithelial cells grown in monolayer culture. Am. J. Physiol. 246 (Cell Physiol. 15):C355-C359.

8. Welsh, M. J. 1985. Ion transport by primary cultures of canine tracheal epithelium: methodology, morphology, and electrophysiology. J. Membr. Biol. 88:149-163.

9. Welsh, M. J. 1983. Barium inhibition of basolateral membrane potassium conductance in tracheal epithelium. Am. J. Physiol. 244 (Renal Fluid Electrolyte Physiol. 13):F639-F645.

10. Widdicombe, J. H., I. T. Nathanson, and E. Highland. 1983. Effects of "loop" diuretics on ion transport by dog tracheal epithelium. Am. J. Physiol. 245 (Cell Physiol. 14):C388-C396.

11. Willumsen, N. J., and R. C. Boucher. 1989. Activation of an apical $\mathrm{Cl}^{-}$ conductance by $\mathrm{Ca}^{2+}$ ionophores in cystic fibrosis airway epithelia. Am. J. Physiol. 256 (Cell Physiol. 25):C226-C233.

12. Smith, J. J., J. D. McCann, and M. J. Welsh. 1990. Bradykinin stimulates airway epithelial $\mathrm{Cl}^{-}$secretion via two second messenger pathways. Am. J. Physiol. 258 (Lung Cell. Mol. Physiol. 2):L369-L377.

13. Widdicombe, J. H. 1986. Cystic fibrosis and $\beta$-adrenergic response of airway epithelial cell cultures. Am. J. Physiol. 251 (Regulatory Integrative Comp. Physiol. 20):R818-R822.

14. Welsh, M. J. 1987. Effect of phorbol ester and calcium ionophore on chloride secretion in canine tracheal epithelium. Am. J. Physiol. 253 (Cell Physiol. 22):C828-C834.

15. Mason, S. J., A. M. Paradiso, H. A. Brown, T. K. Harden, and R. C. Boucher. 1990. Extracellular adenosine triphosphate (ATP) induces calcium release, inositol phosphate production and chloride secretion by cystic fibrosis and normal human airway epithelium. Pediatr. Pulmonol. Suppl. 5:221a. (Abstr.)

16. Welsh, M. J. 1990. Abnormal regulation of ion channels in cystic fibrosis epithelia. FASEB (Fed. Am. Soc. Exp. Biol.) J. 4:2718-2725.

17. Anderson, M. P., D. P. Rich, R. J. Gregory, A. E. Smith, and M. J. Welsh. 1991. Generation of cAMP-activated chloride current by expression of CFTR. Science (Wash. DC). 251:679-682.

18. Kartner, N., J. W. Hanrahan, T. J. Jensen, A. L. Naismith, S. Sun, C. A. Ackerley, E. F. Reyes, L.-C. Tsui, J. M. Rommens, C. E. Bear, and J. R. Riordan. 1991. Expression of cystic fibrosis gene in non-epithelial invertebrate cells produces a regulated anion conductance. Cell. 64:681-691.

19. Anderson, M. P., R. J. Gregory, S. Thompson, D. W. Souza, S. Paul, R. C. Mulligan, A. E. Smith, and M. J. Welsh. 1991. Demonstration that CFTR is a chloride channel by alteration of its anion selectivity. Science (Wash. DC). 253:202-205.

20. Nadel, J. A., J. H. Widdicombe, and A. C. Peatfield. 1985. Regulation of airway secretions. In Handbook of Physiology-The Respiratory System. A. Fishman, editor. American Physiological Society, Bethesda, MD. 424-445.

21. Cullen, J. J., and M. J. Welsh. 1987. Regulation of sodium absorption by canine tracheal epithelium. J. Clin. Invest. 79:73-79.

22. Sleigh, M. A., J. R. Blake, and N. Liron. 1988. The propulsion of mucus by cilia. Am. Rev. Respir. Dis. 137:726-741.

23. Boucher, R. C., M. J. Stutts, P. A. Bromberg, and J. T. Gatzy. 1981. Regional differences in airway surface liquid composition. J. Appl. Physiol. 50:613-620.

24. Pennington, J. E., and H. Y. Reynolds. 1973. Concentration of gentamicin and carbenicillin in bronchial secretions. J. Infect. Dis. 128:63-68.

25. Guerrin, F., C. Voisin, V. Macquet, H. Robin, and P. Lequien. 1971. Apport de la pH metrie bronchique in situ. Prog. Respir. Res. 6:372-383.

26. Luk, C. K., and M. J. Dulfano. 1983. Effect of $\mathrm{pH}$, viscosity and ionicstrength changes on ciliary beating frequency of human bronchial explants. Clin. Sci. (Lond.) 64:449-451.

27. Van de Donk, H. J., J. Zuidema, and F. W. Merkus. 1980. The influence of the $\mathrm{pH}$ and osmotic pressure upon tracheal ciliary beat frequency as determined with a new photoelectric registration device. Rhinology (Rott.) 18:93-104. 